\title{
Prevalence of Musculoskeletal Pain in Construction Workers in Saudi Arabia
}

\author{
Ahmad Alghadir ${ }^{1}$ and Shahnawaz Anwer ${ }^{1,2}$ \\ ${ }^{1}$ Department of Rehabilitation Sciences, College of Applied Medical Sciences, King Saud University, Riyadh, Saudi Arabia \\ ${ }^{2}$ Padmashree Dr. D. Y. Patil College of Physiotherapy, Dr. D. Y. Patil Vidyapeeth, Pune, India
}

Correspondence should be addressed to Shahnawaz Anwer; anwer_shahnawazphysio@rediffmail.com

Received 24 December 2014; Accepted 15 February 2015

Academic Editor: Noureddin Nakhostin Ansari

Copyright ( 2015 A. Alghadir and S. Anwer. This is an open access article distributed under the Creative Commons Attribution License, which permits unrestricted use, distribution, and reproduction in any medium, provided the original work is properly cited.

\begin{abstract}
The objective of this study was to find out the prevalence, characteristics, and distribution of musculoskeletal pain among construction workers in Saudi Arabia. A questionnaire about musculoskeletal pain in different parts of the body was completed by 165 construction workers from the construction industries in Dammam and Riyadh cities. The descriptive data were analyzed using chi-square test. The level of statistical significance was set at $P<0.05$. Eighty $(48.5 \%)$ of the responding workers had pain in neck, shoulders, lower back, hand, knee, or ankle. The majority of respondents had low back pain (50\%) followed by knee pain (20\%). The average intensity of pain at all sites during activity and rest was 6.65 and 3.59, respectively. Thirty-four (42.5\%) respondents had dull aching pain and $24(30 \%)$ had cramping pain. There was an association between years of experience, duration of break during work, and use of protective equipment with the prevalence of musculoskeletal pain in construction workers $(P<0.05)$. Most of the workers complaining of pain got medical treatment $(62.5 \%)$ and only $25 \%$ received physical therapy. It can be concluded from this study that the prevalence of musculoskeletal pain among construction workers in Saudi Arabia is high.
\end{abstract}

\section{Introduction}

Musculoskeletal pain (MSP) is one of the prevailing occupational health problems, and workers in the construction industry have potential risk of MSP. Worldwide, the prevalence of musculoskeletal symptoms involving one or more body regions is higher in construction workers [1]. The load of physical work associated with awkward prolong working postures and manual handling of materials by the construction workers can cause various musculoskeletal pains and disorders [2].

Musculoskeletal disorders (MSDs) cause decreased health and work ability, thereby increasing the costs of absenteeism due to less productivity at work [3]. In the US a nationwide health interview survey showed that construction workers are the highest risk group for work-related low-back pain [4]. In a British study, the 1-year cumulative incidence of low-back pain was $40 \%$ for construction workers as compared with $28 \%$ for managers [5].
Work-related musculoskeletal symptoms are the commonest cause of occupational disability among construction workers [6]. Most studies on work-related musculoskeletal symptoms were limited to office, service, or manufacturing industries. However, the construction industry is considered as one of the most hazardous industries for work-related musculoskeletal symptoms among 10 most frequently reported industries $[7,8]$.

One Indian study reported that four in five construction workers had symptoms of MSDs [9]. Joshi et al. have reported $59.4 \%$ prevalence of MSDs in their study on workers and have suggested that the high prevalence of MSDs in workers needs urgent attention from the health and labor sectors [10]. Aghilinejad et al. [11] reported high rate of musculoskeletal complaints in Iranian aluminum industries. Another study reported potential risk of MSDs in brick field workers in India [12]. Till date no data on work-related musculoskeletal pain is recorded for construction workers among the Saudi population. Our survey aimed to find out prevalence, characteristics, 
and distribution of musculoskeletal pain among construction workers in Saudi Arabia.

\section{Methods}

A descriptive cross-sectional study was used in this research. A sample consisting of 165 male construction workers belonging to 9 main jobs from the construction industries in Dammam and Riyadh cities in the age group of 1860 years was selected and invited to participate in this survey. Participation was completely voluntary and there were no personal identifiers. This study was approved by the institutional ethical committee, King Saud University, and written consent of each subject was taken for their voluntary participation. A questionnaire was developed and validated. The questionnaire included demographic data, personal data, work related history, presence or absence of any musculoskeletal pain in the last 12 months, affected body parts, the intensity of pain on a numerical rating scale (NRS) [13], and any treatment taken. One evaluator conducted faceto-face surveys with structured interviews with construction workers.

2.1. Statistical Analysis. Initial database entry was performed using Excel 2007 (Microsoft Corp, Redmond, WA, USA). Statistical analysis was done using SPSS 22.0 Software (SPSS, IBM Inc.). Descriptive statistics, including proportions, means, medians, and standard deviations, were calculated for age, height, weight, BMI, marital status, job, habit of smoking, educational status, working year, working hours, usual working posture, presence of musculoskeletal pain, affected body part, the intensity of pain, type of pain, and type of treatment taken. The differences in prevalence were analyzed using chi-square tests at statistical significance level of 0.05 .

\section{Results}

Table 1 details the participation characteristics. The sample consisted of 42 (25.5\%) manual laborers, 10 (6.1\%) carpenters, $11(6.7 \%)$ bricklayers, 11 (6.7\%) painters, 21 (12.7\%) electricians, 28 (17\%) plumbers, 10 (6.1\%) interior finish worker, 7 (4.2\%) scaffolders, 15 (9.1\%) crane operators, and $10(6.1 \%)$ others. A hundred and thirty (78.8\%) respondents were married and more than $90 \%$ of respondents were literate. Sixty-three (38.2\%) respondents had a history of smoking.

Table 2 details the prevalence of musculoskeletal pain among respondents. Of the 165 construction workers, 80 $(48.5 \%)$ reported musculoskeletal pain. The majority of respondents had pain in the low back (50\%) followed by knee (20\%), neck (8\%), shoulder (8\%), ankle/foot $(6.3 \%)$, elbow $(2.5 \%)$, hand $(2.5 \%)$, or upper back $(1.6 \%)$. More than $70 \%$ of respondents who reported musculoskeletal pain were in the age group of 30-50 years. The majority of respondents who reported pain were married, overweight, and obese. $45 \%$ of the respondents who reported pain had a history of smoking. Respondents having less than 5 years of working experience reported more pain. Respondents who worked more than 8 hours/day reported more pain. Additionally, respondents
TABLE 1: Participants characteristics.

\begin{tabular}{|c|c|}
\hline \multicolumn{2}{|l|}{ Age, years } \\
\hline Mean (SD) & $34.82(8.33)$ \\
\hline Range & $20-55$ \\
\hline \multicolumn{2}{|l|}{ Height, meter (m) } \\
\hline Mean (SD) & $1.66(0.06)$ \\
\hline Range & $1.50-1.89$ \\
\hline \multicolumn{2}{|l|}{ Weight, kg } \\
\hline Mean (SD) & $72.70(12.75)$ \\
\hline Range & $43-108$ \\
\hline \multicolumn{2}{|l|}{ BMI, $\mathrm{kg} / \mathrm{m}^{2}$} \\
\hline Mean (SD) & $26.13(3.76)$ \\
\hline Range & $17.01-36.51$ \\
\hline \multicolumn{2}{|l|}{ Marital status, number (\%) } \\
\hline Married & $130(78.8)$ \\
\hline Single & $35(21.2)$ \\
\hline \multicolumn{2}{|c|}{ Educational status, number (\%) } \\
\hline Illiterate & $15(9.1)$ \\
\hline Primary & $55(33.3)$ \\
\hline Secondary & $75(45.5)$ \\
\hline Graduation & $20(12.1)$ \\
\hline \multicolumn{2}{|l|}{ Smoking, number (\%) } \\
\hline Yes & $63(38.2)$ \\
\hline No & $102(61.8)$ \\
\hline$<20$ cigarettes/day & $44(69.9)$ \\
\hline$>20$ cigarettes/day & $19(30.1)$ \\
\hline \multicolumn{2}{|l|}{ Type of work, number (\%) } \\
\hline Manual laborer & $42(25.5)$ \\
\hline Plumber & $28(17)$ \\
\hline Electrician & $21(12.7)$ \\
\hline Crane operators & $15(9.1)$ \\
\hline Bricklayers & $11(6.7)$ \\
\hline Painter & $11(6.7)$ \\
\hline Carpenter & $10(6.1)$ \\
\hline Interior finish worker & $10(6.1)$ \\
\hline Scaffolders & $7(4.2)$ \\
\hline Others & $10(6.1)$ \\
\hline
\end{tabular}

who took more than 20 minutes break during work reported less pain. Also $55 \%$ of respondents who reported pain were using protective equipment.

Table 3 details the characteristics and consequences of musculoskeletal pain in construction workers. The majority of respondents had low back pain (50\%) followed by knee pain $(20 \%)$. The average intensity of pain during activity and rest was 6.65 and 3.59, respectively. Most of the respondents had periodic pain $(50 \%)$ followed by regular pain $(28.8 \%)$. The duration of pain persisted for 2-4 days in most of the workers (47.5\%). Thirty-four (42.5\%) respondents had dull aching pain and 24 (30\%) had cramping pain. Thirtyeight $(47.5 \%)$ respondents who reported pain took more than 15 -day sick leave in last 12 months. However, $45 \%$ of the respondents who reported pain did not take any sick leave. The analysis of the questions related to the usual position of 
TABLE 2: Prevalence of musculoskeletal pain among respondents.

\begin{tabular}{|c|c|c|c|}
\hline Variables & Yes $(\%)$ & No $(\%)$ & Chi-square test \\
\hline Musculoskeletal pain & $80(48.5)$ & $85(51.5)$ & $P$ value \\
\hline Age, years & & & 0.137 \\
\hline $20-29$ & $20(25)$ & $32(37.6)$ & \\
\hline $30-39$ & $31(38.7)$ & $32(37.6)$ & \\
\hline $40-49$ & $26(32.6)$ & $16(18.8)$ & \\
\hline $50-59$ & $3(3.7)$ & $5(5.8)$ & \\
\hline Marital status & & & 0.258 \\
\hline Married & $66(82.5)$ & $64(75.2)$ & \\
\hline Single & $14(17.5)$ & $21(24.8)$ & \\
\hline Educational status & & & 0.206 \\
\hline Illiterate & $9(11.2)$ & $6(7.2)$ & \\
\hline Primary & $22(27.5)$ & $33(38.8)$ & \\
\hline Secondary & $36(45)$ & $39(45.8)$ & \\
\hline Graduation & $13(16.3)$ & $7(8.2)$ & \\
\hline BMI & & & 0.174 \\
\hline Underweight & $2(2.5)$ & $0(0)$ & \\
\hline Normal weight & $26(32.5)$ & $38(44.7)$ & \\
\hline Over weight & $35(43.7)$ & $35(41.1)$ & \\
\hline Obese & $17(21.2)$ & $12(14.1)$ & \\
\hline Smoking & & & 0.080 \\
\hline Yes & $36(45)$ & $27(31.8)$ & \\
\hline No & $44(55)$ & $58(68.2)$ & \\
\hline Type of work & & & 0.565 \\
\hline Manual laborer & $20(25)$ & $22(25.8)$ & \\
\hline Plumber & $16(20)$ & $12(14.1)$ & \\
\hline Electrician & $8(10)$ & $13(15.3)$ & \\
\hline Crane operators & $9(11.2)$ & $6(7)$ & \\
\hline Bricklayers & $7(8.7)$ & $4(4.7)$ & \\
\hline Painter & $7(8.7)$ & $4(4.7)$ & \\
\hline Carpenter & $3(3.7)$ & $7(8.2)$ & \\
\hline Interior finish worker & $3(3.7)$ & $7(8.2)$ & \\
\hline Scaffolders & $3(3.7)$ & $4(4.7)$ & \\
\hline Others & $4(5)$ & $6(7)$ & \\
\hline Years of experience & & & $0.011^{*}$ \\
\hline$>5$ years & $39(48.8)$ & $25(29.4)$ & \\
\hline$<5$ years & $41(51.2)$ & $60(70.6)$ & \\
\hline Working hours/day & & & 0.603 \\
\hline$>8$ hour/day & $41(51.2)$ & $47(55.3)$ & \\
\hline$<8$ hour/day & $39(48.8)$ & $38(44.7)$ & \\
\hline Duration of break during work & & & $0.002^{*}$ \\
\hline$>20$ minutes & $30(37.5)$ & $16(18.9)$ & \\
\hline$<20$ minutes & $50(62.5)$ & $69(81.1)$ & \\
\hline Use of protective equipment & & & $0.001^{*}$ \\
\hline Yes & $44(55)$ & $67(78.9)$ & \\
\hline No & $36(45)$ & $18(21.1)$ & \\
\hline
\end{tabular}

${ }^{*} P<0.05$.

work showed that the most frequently used postures were standing and sitting postures (65\% and $37 \%$, resp.). Fifty $(62.5 \%)$ workers complaining of pain got medical treatment; only $25 \%$ got physical therapy.

\section{Discussion}

This survey aimed to find out the prevalence, characteristics, and distribution of musculoskeletal pain among construction 
TABLE 3: Characteristics and consequences of musculoskeletal pain in construction workers.

\begin{tabular}{|c|c|}
\hline & $\begin{array}{c}\text { Musculoskeletal } \\
\text { pain sufferers, } \\
N=80 \\
\end{array}$ \\
\hline \multicolumn{2}{|c|}{ Location of pain, number (\%) } \\
\hline Neck & $7(8.8)$ \\
\hline Shoulder & $7(8.8)$ \\
\hline Upper back & $1(1.3)$ \\
\hline Elbow & $2(2.5)$ \\
\hline Hand & $2(2.5)$ \\
\hline Low back & $40(50)$ \\
\hline Knee & $16(20)$ \\
\hline Ankle/foot & $5(6.3)$ \\
\hline \multicolumn{2}{|c|}{$\begin{array}{l}\text { Average intensity of pain during activity, NRS } \\
(0-10) \text {, number }(\%)\end{array}$} \\
\hline $1-3$ & $2(2.5)$ \\
\hline $4-6$ & $33(41.3)$ \\
\hline $7-10$ & $45(56.3)$ \\
\hline \multicolumn{2}{|c|}{$\begin{array}{l}\text { Average intensity of pain at rest, NRS (0-10), } \\
\text { number }(\%)\end{array}$} \\
\hline $1-3$ & $38(47.5)$ \\
\hline $4-6$ & $41(51.3)$ \\
\hline $7-10$ & $1(1.3)$ \\
\hline \multicolumn{2}{|c|}{ Frequency of pain, number (\%) } \\
\hline Occasional & $40(50)$ \\
\hline Often & $23(28.8)$ \\
\hline Sometimes & $11(13.8)$ \\
\hline Always & $6(7.5)$ \\
\hline \multicolumn{2}{|c|}{ Duration of pain, number (\%) } \\
\hline$<2$ hours & $20(25)$ \\
\hline$>2$ hours & $6(7.5)$ \\
\hline 2-4 days & $38(47.5)$ \\
\hline$>1$ week & $16(20)$ \\
\hline \multicolumn{2}{|c|}{ Type of pain, number (\%) } \\
\hline Cramping & $24(30)$ \\
\hline Dull aching & $34(42.5)$ \\
\hline Shooting & $16(20)$ \\
\hline Burning & $6(7.5)$ \\
\hline \multicolumn{2}{|c|}{ Sick leave, number (\%) } \\
\hline Nil & $36(45)$ \\
\hline$<15$ days & $6(7.5)$ \\
\hline$>15$ days & $38(47.5)$ \\
\hline \multicolumn{2}{|c|}{ Any kind of treatment taken, number (\%) } \\
\hline Medical & $50(62.5)$ \\
\hline Physiotherapy & $20(25)$ \\
\hline Others & $10(12.5)$ \\
\hline
\end{tabular}

workers in Saudi Arabia. The 12-month prevalence of musculoskeletal pain in construction workers was high (48.5\%). Our findings are consistent with the previous cross-sectional questionnaire based study that reported a similar prevalence of musculoskeletal complaints in construction workers [1417]. Merlino et al. [18] and Bodhare et al. [9] reported very high prevalence of musculoskeletal disorders with $76.8 \%$ and $77 \%$, respectively. In contrast, Guo et al. [7] reported a little lower prevalence of musculoskeletal disorders of $37 \%$.

In the present study, the most common site of pain was lower back which is similar to previous findings among construction workers $[4,14,15,17-23]$. The prevalence of knee pain in this study was high (20\%) after the lower back. This finding is in agreement with those of Merlino et al. [18] who reported high prevalence of knee pain (38.4\%) after low back pain in their samples of young construction workers.

In this study, we investigated the average intensity of pain during activity and rest among construction workers. The average intensity of pain during activity was more than 7 on NRS in $56.3 \%$ of construction workers. The average intensity of pain at rest was $4-6$ on NRS in $51.3 \%$ of them. The intensity of pain is useful to get an insight into the severity of the musculoskeletal symptoms. The high intensity of pain during activity and at rest in the present study suggests that construction workers are at risk of severe musculoskeletal disorders. However, this important aspect was not investigated previously.

The average duration of pain was 2-4 days in $47.5 \%$ construction workers, for which they took more than 15 days sick leave over last 12 months. In the present study, the most prevalent type of pain was dull aching (42.5\%) followed by cramping $(30 \%)$. The type of pain can give us a clue to determine which structures are affected. Also this aspect of pain was not investigated previously.

The present study found an association between years of experience, duration of break during work, and use of protective equipment with the prevalence of musculoskeletal pain in construction workers. The workers who had worked more than 5 years had an increased prevalence of MSP. On the other hand, those who took longer break durations ( $>20$ minutes) and used protective equipment during work reported less MSP. In a previous study, Kaminskas and Antanaitis [16] reported an association between musculoskeletal pain and years in the construction industry. The prevalence of musculoskeletal pain was $33 \%$ in workers who work less than 5 years in the industry. The prevalence increases to $40 \%$ when working years are 6-10 years. The prevalence further increases to $84 \%$ when the working years increase to 30 years. However, in the present study we categorized working years into two groups: less than 5 years and more than 5 years. No study previously investigated the association of MSP with duration of the break and usage of protective equipment during work. However, these two could be important factors to prevent the occurrence of work related MSP.

There are several limitations to the present study. The study was limited to only male respondents. The cause and effect cannot be established as this study was a cross-sectional study. The different circumstances of questionnaire administration such as self-reported or interview-based should be considered and the comparison of results should always be made with some caution. The questionnaire administered through interviews, as in this study, instead of self-reported, can ensure greater validity of the answers. 


\section{Conclusions}

It can be concluded that the prevalence of musculoskeletal pain among construction workers in Saudi Arabia is high. The majority of respondent had low back pain followed by knee pain. The high intensity of pain during activity and at rest in the present study suggests that construction workers are at risk of severe musculoskeletal disorders. The most prevalent type of pain was dull aching followed by cramping. There was an association of years of experience, duration of break during work, and use of protective equipment with the prevalence of musculoskeletal pain in construction workers.

\section{Conflict of Interests}

The authors declared that there is no conflict of interests regarding the publication of this paper.

\section{Acknowledgments}

The authors extend their appreciation to the College of Applied Medical Sciences Research Centre and the Deanship of Scientific Research at King Saud University for funding this research. This work is supported by Research Centre, College of Applied Medical Sciences, King Saud University.

\section{References}

[1] D. Goldsheyder, M. Nordin, S. S. Weiner, and R. Hiebert, "Musculoskeletal symptom survey among mason tenders," American Journal of Industrial Medicine, vol. 42, no. 5, pp. 384-396, 2002.

[2] W. S. Marras, W. G. Allread, D. L. Burr, and F. A. Fathallah, "Prospective validation of a low-back disorder risk model and assessment of ergonomic interventions associated with manual materials handling tasks," Ergonomics, vol. 43, no. 11, pp. 18661886, 2000.

[3] L. Punnett and D. H. Wegman, "Work-related musculoskeletal disorders: the epidemiologic evidence and the debate," Journal of Electromyography and Kinesiology, vol. 14, no. 1, pp. 13-23, 2004.

[4] S. Ueno, N. Hisanaga, H. Jonai, E. Shibata, and M. Kamijima, "Association between musculoskeletal pain in Japanese construction workers and job, age, alcohol consumption, and smoking," Industrial Health, vol. 37, no. 4, pp. 449-456, 1999.

[5] G. J. Macfarlane, E. Thomas, A. C. Papageorgiou, P. R. Croft, M. I. V. Jayson, and A. J. Silman, "Employment and physical work activities as predictors of future low back pain," Spine, vol. 22, no. 10, pp. 1143-1149, 1997.

[6] V. Arndt, D. Rothenbacher, U. Daniel, B. Zschenderlein, S. Schuberth, and H. Brenner, "Construction work and risk of occupational disability: a ten year follows up of 14,474 male workers," Occupational and Environmental Medicine, vol. 62, no. 8, pp. 559-566, 2005.

[7] H. R. Guo, Y. C. Chang, W. Y. Yeh, C. W. Chen, and Y. L. Guo, "Prevalence of musculoskeletal disorder among workers in Taiwan: a national study," Journal of Occupational Health, vol. 46, no. 1, pp. 26-36, 2004.

[8] Y. Chen, S. Turner, L. Hussey, and R. Agius, "A study of work-related musculoskeletal case reports to The Health and Occupation Reporting network (THOR) from 2002 to 2003," Occupational Medicine, vol. 55, no. 4, pp. 268-274, 2005.
[9] T. Bodhare, S. Valsangkar, and S. Bele, "An epidemiological study of work-related musculoskeletal disorders among construction workers in Karimnagar, Andhra Pradesh," Indian Journal of Community Medicine, vol. 36, no. 4, pp. 304-307, 2011.

[10] K. T. Joshi, K. K. Menon, and J. Kishore, "Musculoskeletal disorders in industrial workers of Delhi," International Journal of Occupational and Environmental Health, vol. 7, no. 3, pp. 217221, 2001

[11] M. Aghilinejad, S. A. J. Mousavi, M. K. Nouri, and A. B. Ahmadi, "Work-related musculoskeletal complaints among workers of Iranian aluminum industries," Archives of Environmental and Occupational Health, vol. 67, no. 2, pp. 98-102, 2012.

[12] B. Das, "Prevalence of work-related musculoskeletal disorders among the brick field workers of West Bengal, India," Archives of Environmental \& Occupational Health, vol. 69, no. 4, pp. 231240, 2014.

[13] C. H. Gallasch and N. M. C. Alexandre, "The measurement of musculoskeletal pain intensity: a comparison of four methods," Revista Gaúcha de Enfermagem, vol. 28, no. 2, pp. 260-265, 2007.

[14] U. Latza, W. Karmaus, T. Stürmer, M. Steiner, A. Neth, and U. Rehder, "Cohort study of occupational risk factors of low back pain in construction workers," Occupational and Environmental Medicine, vol. 57, no. 1, pp. 28-34, 2000.

[15] J. S. Boschman, H. F. van der Molen, J. K. Sluiter, and M. H. Frings-Dresen, "Musculoskeletal disorders among construction workers: a one-year follow-up study," BMC Musculoskeletal Disorders, vol. 13, article 196, 2012.

[16] K. A. Kaminskas and J. Antanaitis, "A cross-sectional survey of construction workers: an ergonomics approach," in Proceedings of the 10th International Conference on "Modern Building Materials, Structures and Techniques", pp. 1246-1252, Vilnius, Lithuania, May 2010.

[17] R. D. C. P. Fernandes, F. M. Carvalho, and A. Á. Assunção, "Prevalence of musculoskeletal disorders among plastics industry workers," Cadernos de Saude Publica, vol. 27, no. 1, pp. 78-86, 2011.

[18] L. A. Merlino, J. C. Rosecrance, D. Anton, and T. M. Cook, "Symptoms of musculoskeletal disorders among apprentice construction workers," Applied Occupational and Environmental Hygiene, vol. 18, no. 1, pp. 57-64, 2003.

[19] G. C. Harold and N. U. Daniel, "A survey on the prevalence of musculoskeletal disorders among building construction workers in Anambra state," International Journal of Advanced Engineering Technology, vol. 4, pp. 11-15, 2013.

[20] C. Leboef, N. Klougart, and N. Lauritzen, "How common is low back pain in the Nordic population?" Spine, vol. 13, pp. 15181526, 1996.

[21] D. Rothenbacher, H. Brenner, V. Arndt, E. Fraisse, B. Zschenderlein, and T. M. Fliedner, "Disorders of the back and spine in construction workers: prevalence and prognostic value for disability," Spine, vol. 22, no. 13, pp. 1481-1486, 1997.

[22] J. S. Petersen and C. Zwerling, "Comparison of health outcomes among older construction and blue-collar employees in the United States," American Journal of Industrial Medicine, vol. 34, no. 3, pp. 280-287, 1998.

[23] I. W. H. Fung, V. W.-Y. Tam, C. M. Tam, and K. Wang, "Frequency and continuity of work-related musculoskeletal symptoms for construction workers," Journal of Civil Engineering and Management, vol. 14, no. 3, pp. 183-187, 2008. 


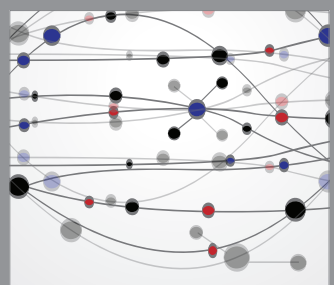

The Scientific World Journal
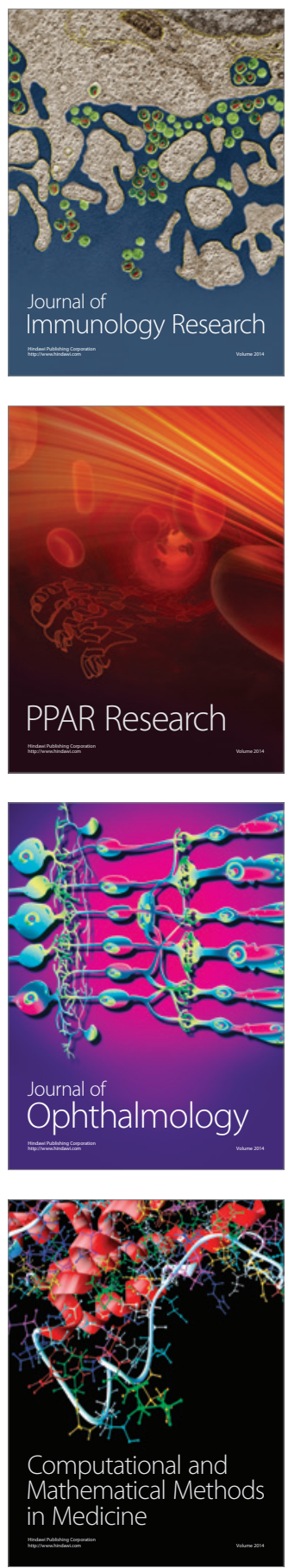

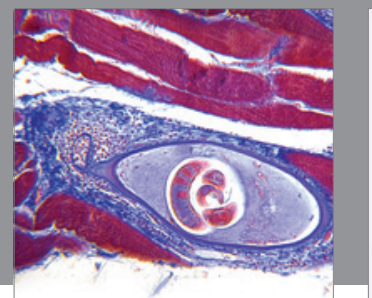

Gastroenterology

Research and Practice
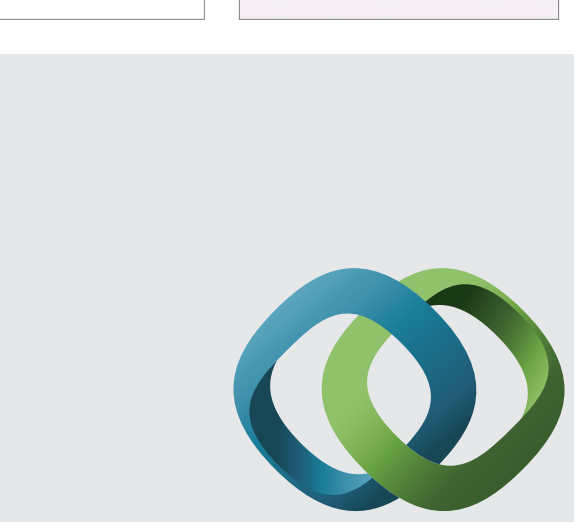

\section{Hindawi}

Submit your manuscripts at

http://www.hindawi.com
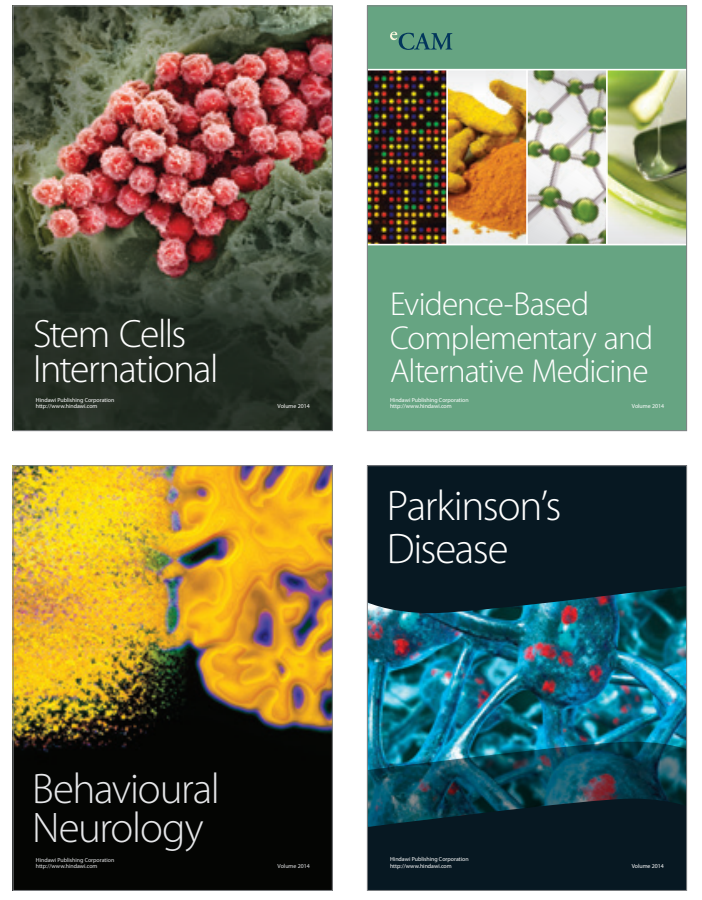
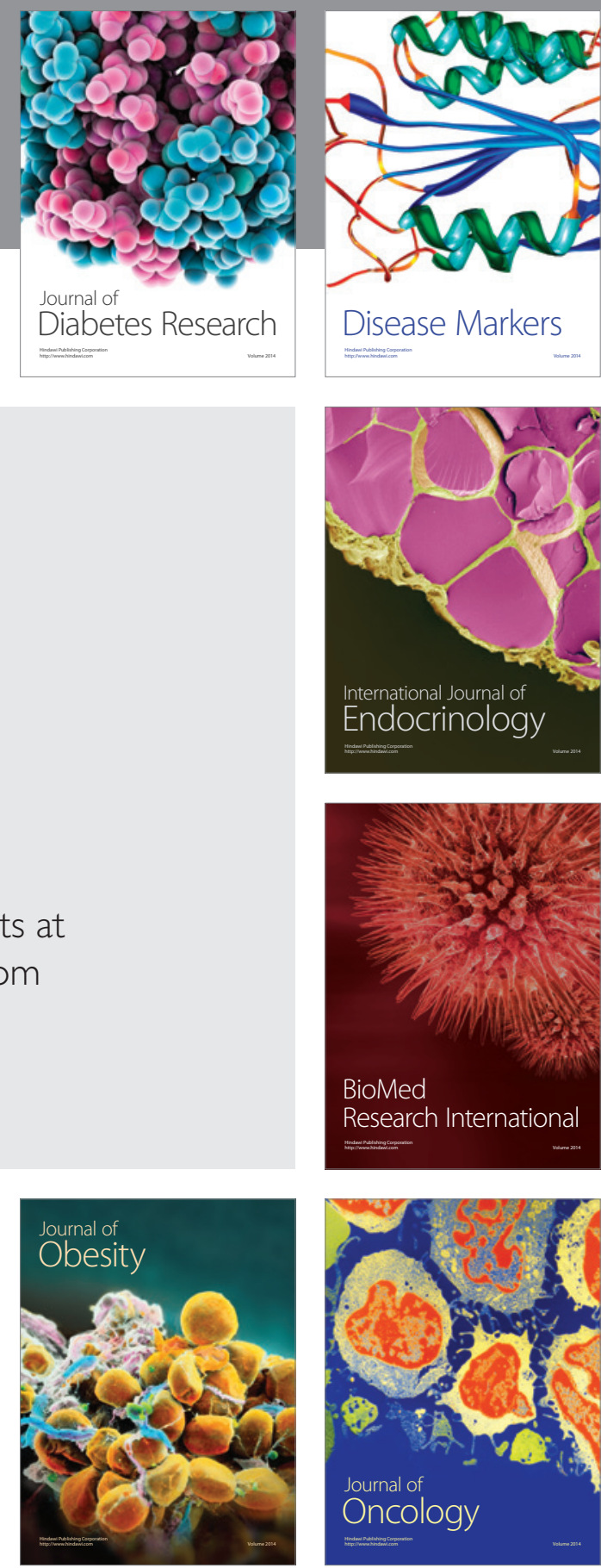

Disease Markers
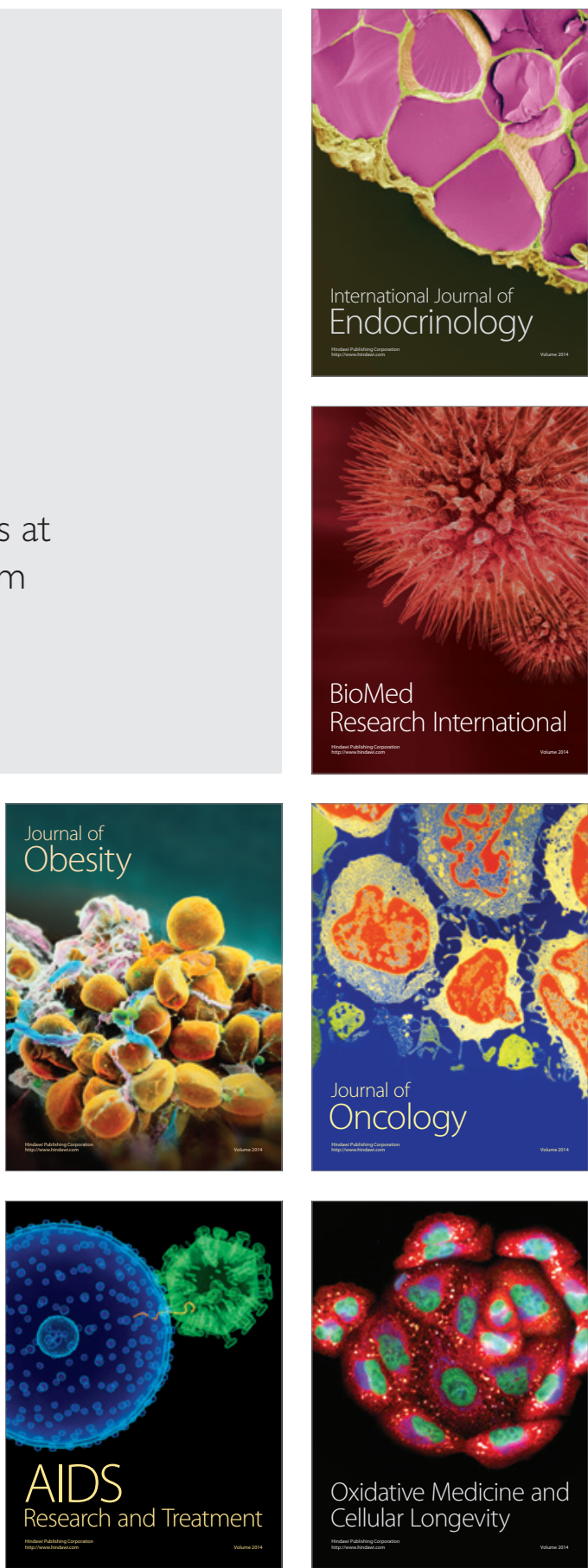